\title{
Unveiling Key Drivers of Indirect Carbon Emissions of Chinese Older Households
}

\author{
Hongwu Zhang ${ }^{1}$, Lequan Zhang ${ }^{1}$, Keying Wang ${ }^{2,3, *(1)}$ and Xunpeng Shi ${ }^{2,4}$ \\ 1 School of Economics, Zhongnan University of Economics and Law, Wuhan 430073, China; \\ hongwuzhang@zuel.edu.cn (H.Z.); lequanzhang@foxmail.com (L.Z.) \\ 2 Center of Hubei Cooperative Innovation for Emissions Trading System, Hubei University of Economics, \\ Wuhan 430205, China \\ 3 School of Low Carbon Economics, Hubei University of Economics, Wuhan 430205, China \\ 4 Australia-China Relations Institute, University of Technology Sydney, Sydney, NSW 2007, Australia; \\ xunpeng.shi@uts.edu.au \\ * Correspondence: wangkeying@126.com
}

Received: 5 September 2019; Accepted: 14 October 2019; Published: 17 October 2019

\begin{abstract}
The rapid urbanization and growing population aging have become salient features in China. Understanding their impacts on household emissions is crucial for designing mitigation policies for household carbon emissions. By integrating Chinese older household survey data with an unconditional quantile regression model, this paper examines the heterogeneous impacts of household characteristics on indirect carbon emissions of older Chinese households. There are three main findings: (1) The effects of urbanization on emissions at different quantiles of carbon emissions appear to be inverted U-shaped, which means that the rise of urbanization level increases carbon emissions more at the middle than at the bottom or the top, and helps to alleviate carbon emission inequality, (2) though carbon emissions rise with the increase of income, there is a clear urban-rural divide in the effects of income on carbon emissions, and (3) the rise in the share of well-educated people contributes to the increase in carbon emissions. The higher the degree of education is, the larger the impact is. These findings contribute to understanding the determinants of carbon emissions and are helpful for policymakers to design targeted policies in reducing carbon emissions from the consumption-side.
\end{abstract}

Keywords: indirect carbon emissions; older households; low carbon policy; unconditional quantile regression

\section{Introduction}

Studying the indirect carbon emissions of the household and its key drivers becomes increasingly important, particularly for China. Deep cuts in carbon emissions are unlikely to be fulfilled through technological change alone. Reducing carbon emissions from households attracts considerable attention recently [1]. Given that the sole purpose of all production is ultimately consumption, a majority of energy utilization and the associated carbon emissions in a country come from the household sector (more than $80 \%$ for U.S. [2], 75\% for India [3], 52\% for Korea [4], and 61\% for Japan [5]), the need to cut carbon emissions from the consumption-side has been emphasized lately [6]. Moreover, studies show that indirect, or embedded energy consumption and the related carbon emissions of households are becoming increasingly important in designing effective emission reduction policies. For example, indirect carbon emissions constitute the $71 \%$ to $78 \%$ of household carbon footprints in Greece during the study period 1995-2012 [7], and most of China's household energy utilization is also indirect [8]. Indirect carbon abatement is especially important and challenging for China in achieving its emission 
reduction target. China is the largest emitter of $\mathrm{CO}_{2}$ in the world, and it has recently laid a strong emphasis on the promotion of domestic consumption and economic growth, which will continuously give rise to the direct and indirect $\mathrm{CO}_{2}$ emissions from households. Considering that indirect $\mathrm{CO}_{2}$ emissions are responsible for a major part of the total emissions, the carbon emission reduction target cannot be fulfilled without special attention to the increasing indirect carbon emissions.

It is of vital significance to study the determinants of indirect $\mathrm{CO}_{2}$ emissions of Chinese older households. China is experiencing both rapid urbanization and growing population aging, which have a crucial influence on carbon emissions. In addition to the significant impact of urbanization on resident consumption and carbon emissions, there is evidence that the rapid shrinking of the younger generation and the rapid growth in the older population will put increasing pressure on the environment $[9,10]$. Meanwhile, the consumption behavior of older people is clearly different from that of other groups, and it is predicted that changes in age structure in the coming decades will affect household consumption patterns and the related carbon emissions in many countries [11].

This paper synthesizes three corpus of literature on household energy consumption or carbon emissions. First, some studies focus on approaches to quantify the indirect carbon emissions from household consumption activities. In summary, three kinds of major approaches are widely used in different countries or regions [12], which are the input-output model, the life cycle assessment method, and the consumer lifestyle approach. Based on the input-output model, Yuan et al. calculated the regional indirect carbon emissions from residential consumption in China in 2002 and 2007 [13]. Ma et al. estimated and compared the carbon emissions from household energy consumption in 2002, 2005, 2007, and 2010 between China and the USA [14]. By employing the life cycle assessment method, Shen et al. quantified the $\mathrm{CO}_{2}$ emissions from China's cement industry in 2011 [15]. Heinonen et al. presented a carbon consumption comparison of rural and urban lifestyles in Finland [16]. As for the application of the consumer lifestyle approach, Feng et al. analyzed the impact of consumption by urban and rural households on energy use and $\mathrm{CO}_{2}$ emissions for different regions and income levels in China [17]. $\mathrm{Xu}$ et al. surveyed the household carbon inequality in urban China and analyzed its sources and determinants using weighted household survey data [18]. Second, several empirical studies conduct comparative analyses on differences in household carbon emissions among various income groups. By using survey data on Chinese urban households, Golley and Meng investigated variations in carbon emissions across households with different incomes [19]. Zhang et al. estimated carbon emissions from rural energy utilization in various regions of China, and found significant regional disparities in carbon emissions due to differences in regional climates and economic development levels [20]. By grouping the provinces in mainland China into four economic regions, Yuan et al. explored the regional variations of impacts of urbanization, the consumption ratio, and the consumption structure on residential indirect carbon emissions from 2002 to 2007 [13]. By applying the structural decomposition model, Wang et al. examined the driving forces that affect $\mathrm{CO}_{2}$ emissions from China's residential consumption in the context of sustainable consumption [21]. Ma et al. analyzed the differences of indirect carbon emissions from household consumption in 2002, 2005, 2007, and 2010 between the USA and China [14]. Lopez et al. assessed household carbon footprints for different income groups before and after the Great Recession in Spain [22]. Wiedenhofer et al. presented distribution-focused carbon footprints for Chinese households and applied a carbon-footprint-Gini coefficient to measure inequalities in carbon emissions [23]. Sommer and Kratena calculated the carbon footprints of private consumption in the EU27 through five income groups of households, and found that there is a non-linear income elasticity of emissions at each income level [24].

Third, several studies apply survey data to study the relationship between household carbon emissions and its influencing factors. Brand et al. examined the association between household socioeconomic factors and household direct or indirect carbon emissions in the UK [25]. Sun et al. applied the Tobit and OLS models to examine the influencing factors of direct energy expenditures in China and found that urbanization is the main driving factor [26]. In a comparative analysis, Han et al. showed how household characteristics differ in their associations with indirect carbon emissions at 
different levels of income by applying a conditional quantile regression (CQR) [27]. Allison et al. showed that there are differences in the relative contributions of gas, electricity, and personal transport to household total carbon emissions, respectively [28]. Olaniyan et al. concluded that income, family size, motorization, and the literacy ratio are the major driving factors of household carbon emissions in Nigeria [29]. Christis et al. demonstrated that some socioeconomic factors such as the level of education and household size are closely related to income distribution, which has an important impact on household carbon footprints in Belgium [30]. The relationship between education and carbon emissions, however, is not conclusive. Baiocchi et al. discovered that education and total carbon emissions are positively correlated, yet high education tends to reduce emissions, which shows the hypothesis that awareness of environmental problems rises with high education [31]. Brand and Preston demonstrated that people who attended university or full-time education (a proxy for high education) have significantly higher transportation emissions [32]. Lenzen et al. found a negative association between emissions and high education for Australia but a positive association for Brazil and India, arguing that high education is a privilege of the rich in the latter and, thus, is related to high emissions. This suggests that the relationship between education and energy requirements is not clear cut [33]. Golley and Meng discovered that the education level of the household head has a significant positive impact on household indirect carbon emissions. Büchs and Schnepf illustrated that high education is positively related to all areas of emissions, which suggests that increasing the education level alone is unlikely to tackle household carbon emissions [34]. Boehm et al. found that white households and those with higher education levels generate more greenhouse gas emissions from food spending compared to non-white and less educated households [35]. In addition, some studies focus on the impact of age on household $\mathrm{CO}_{2}$ emissions. Yu et al. discovered that the transition of households to small size and aging leads to rapid growth in energy utilization and $\mathrm{CO}_{2}$ emissions [36]. Büchs and Schnepf illustrated that low income, jobless, and elderly families tend to have higher emissions [34]. Wilson et al. found that household size, income, age, and marital status are all statistically correlated with the direct $\mathrm{CO}_{2}$ emissions in Canada [37].

Some influencing factors of household carbon emissions such as income, education, and rural/urban location are related with each other. While bivariate analysis may find that each of these characteristics is associated with emissions, multivariate analysis is required to determine whether or not characteristics such education or rural location remain associated with emissions after income is controlled for [34]. Therefore, multivariate analysis is applied to control for relationships between different factors. Previous studies show that the multivariate ordinary least square (OLS) regression is widely used in the determinants of household $\mathrm{CO}_{2}$ emissions [19]. However, it is a kind of mean reversion method, which treats the effects of influencing factors on carbon emissions as the same, irrespective of the distribution of the outcome variable, which makes the results less accurate and complete. Even if some studies applied CQR [27], the interpretation of the coefficients is still limited, which leads to the results not generalizable or interpreted in a policy or population context. As a result, the estimated effects from the OLS regression or CQR are not enough to present relevant policy suggestions related to these covariates.

By integrating Chinese older household survey data with an unconditional quantile regression (UQR) model, this paper aims to examine the heterogeneous effects of household characteristics on the indirect carbon emissions of Chinese older households. We made efforts to contribute to the literature that focus on $\mathrm{CO}_{2}$ emission reduction from the perspective of the consumption side in the context of urbanization and population aging, which provides more realistic and meaningful insights for policymakers. Our second contribution is the insights that are revealed through the application of the UQR methodology. It seems very unlikely that high-carbon households and low-carbon households react to changes in influencing factors of $\mathrm{CO}_{2}$ emissions in the same way that the prevailing OLS method reveals. For example, Zheng et al. discovered that the distributions per capita carbon emissions at the 10th and 90th quantiles are very different [38]. Based on the quantile regression model, $\mathrm{Xu}$ and Han evaluated the heterogeneous impacts of consumer credit on household carbon emissions [39]. 
Rong et al. employed the quantile regression model to analyze the influencing factors of indirect household carbon emissions and found that household features, housing characteristics, lifestyles, and consumption patterns have different impacts on per capita household carbon emissions [40]. More importantly, Borah and Basu demonstrated that, even if CQR can help understand the differential effects of covariates along with the distribution of a response variable, it may generate results that are often not generalizable or interpretable in a policy or population context [41].

The paper is structured as follows. Section 2 provides the methodology and data. Section 3 presents the empirical results on the effects of urbanization on carbon emissions over different quantiles, and also discusses the key drivers of the household indirect $\mathrm{CO}_{2}$ emissions in urban and rural areas, respectively. Section 4 provides further discussions and policy implications.

\section{Materials and Methods}

\subsection{Calculation of Indirect Carbon Emissions}

To quantify the indirect carbon emissions of Chinese older households, we first determine sector-specific carbon emission intensities by means of input-output (IO) analysis and total carbon emissions for each sector from the world input-output database (WIOD) [42]. We then link these sector-specific carbon emission intensities to data on household expenditures to obtain the $\mathrm{CO}_{2}$ emissions of different households.

As stated in the introduction, indirect $\mathrm{CO}_{2}$ emissions are mainly calculated in three ways, and the advantage of the IO method lies in the complete and systematic coverage of the entire upstream supply chains especially of all the indirect linkages. In this paper, we rely on IO analysis to identify each household's $\mathrm{CO}_{2}$ emissions embedded in the production of goods and services, and calculate $C_{k}$. The indirect $\mathrm{CO}_{2}$ emissions of a specific household $k$ are as follows.

$$
C_{k}=D(I-A)^{-1} E_{k}
$$

where $D$ is the row vector of direct emission intensities in each sector, and $A$ is the inter-sector matrix of direct input coefficients, Thus, $(I-A)^{-1}$ is the Leontief inverse matrix. $E_{k}$ is the household $k^{\prime} s$ consumption expenditures on goods and services.

\subsection{Unconditional Quantile Regression}

To design effective $\mathrm{CO}_{2}$ emission reduction policies, policymakers need to know which household features are related to $\mathrm{CO}_{2}$ emissions. Furthermore, since the impacts of household features on carbon emissions are not the same at various levels of $\mathrm{CO}_{2}$ emissions, it is necessary to analyze the differential effects of covariates along with the distribution of carbon emissions. Compared with CQR, UQR gives more interpretable results as it marginalizes the effects over the distributions of other covariates in the model.

Quantile regression, which was introduced by Koenker and Bassett [43], presents a pragmatic approach for understanding the differential effects of covariates along with the distribution of an outcome. For the purpose of estimating $\mathrm{CQR}$, the $\tau$ th conditional quantile of a random variable $Y$ (e.g., household carbon emissions) is assumed to be a linear function of randomly distributed exogenous factors $X$ (e.g., income, age).

$$
q_{Y \mid X}(\tau)[Y]=X \beta_{\tau},
$$

where $\tau$ takes values between 0 and $1,0<\tau<1$. The equation implies that the carbon emissions $y_{i}$ of household $i$ with $\tau=\tau_{i}$ are exactly equal to $x_{i} \beta_{\tau_{i}}$, where $x_{i}$ s are the characteristics of household $i$. Similar to the standard OLS, the parameter $\beta_{\tau}$ are estimated by minimizing the following criteria.

$$
\underset{\beta_{\tau}}{\operatorname{argmin}} \sum_{i} \rho_{\tau}\left(y_{i}-x_{i} \beta_{\tau}\right)
$$


where $\rho_{\tau}\left(y_{i}-x_{i} \beta_{\tau}\right)=\left(y_{i}-x_{i} \beta_{\tau}\right)(\tau-1)$ if $y_{i} \leq x_{i} \beta_{\tau}$ and $\rho_{\tau}\left(y_{i}-x_{i} \beta_{\tau}\right)=\left(y_{i}-x_{i} \beta_{\tau}\right) \tau$ if $y_{i}>x_{i} \beta_{\tau}$.

$\mathrm{CQR}$ allows the coefficient estimate $\beta_{\tau}$ to be different for different quantile functions. However, it can only be used to measure the effect of a covariate on the quantile of the outcome conditions on specific values of other covariates and may generate results that are not easy to generalize or explain in a policy or population context. In contrast, the UQR method provides more interpretable results, as the object of interest of UQR is the marginal effect on the unconditional quantile of a small increase in the characteristics $X$.

$$
\beta(t)=\lim _{t \rightarrow 0} \frac{q \gamma_{\tau}[h(X+t, \varepsilon)]-q_{\Upsilon_{\tau}}[h(X, \varepsilon)]}{t},
$$

where carbon emissions $Y$ are a function of observed features $X$ and unobserved features $\varepsilon$, and $q_{\Upsilon \tau}[Y]$ is the $\tau$ th quantile of the unconditional distribution of $Y$. The method is rather general since it does not only investigate the impact on a particular quantile but also on other measures of the carbon emissions' distribution such as the mean. Moreover, the quantile regression techniques are fairly robust when compared to the outliers, which is a highly desirable property given the use of household survey data prone to a measurement error.

The unconditional marginal effect is estimated using the two-step procedure proposed by Firpo et al. [44]. The first stage involves estimating the re-centered influence function (RIF) for each individual.

$$
R I F=q_{Y_{\tau}}+\frac{\tau-1}{f_{Y}\left(q_{Y_{\tau}}\right)} \text { if } Y \leq q_{Y_{\tau}} \text { and } R I F=q_{Y_{\tau}}+\frac{\tau}{f_{Y}\left(q_{Y_{\tau}}\right)} \text { if } Y>q_{Y_{\tau}}
$$

where the density of carbon emissions $f_{Y}$ is measured using a Gaussian kernel estimator. In the second stage, the RIF is regressed on the explanatory variables $X$ using OLS, and, hence, the probability for an individual to have carbon emissions above a certain quantile is assumed to be linear in the observed characteristics. Since the RIF takes only two different values, a logistic estimator is a natural choice for the second-stage estimation.

\subsection{Data Sources and Processing}

We adopt data from a variety of sources in this paper. First, we obtain survey data from the China Health and Retirement Longitudinal Study (CHARLS) for 2013, which was performed by Peking University. The main respondents in CHARLS are aged 45 or older, and it is high-quality survey data that provides families and individuals information of middle-aged and older people in China. At the same time, CHARLS presents detailed household expenditures on 24 items of goods and service, from which we can estimate household $\mathrm{CO}_{2}$ emissions and incomes. The survey data also provides household demographic features and certain other socio-economic characteristics. Based on Duarte et al. [45] and $\mathrm{Xu}$ et al. [46], the determinants of the household $\mathrm{CO}_{2}$ emissions in China selected are income, age, education, household size, and the location of the economic regions. Whether the household resides in urban or rural areas is also included. These variables and their descriptions are shown in Table 1. 
Table 1. Description of variables.

\begin{tabular}{|c|c|}
\hline Variables & Descriptions \\
\hline $\mathrm{CO}_{2}$ & Household indirect carbon emissions \\
\hline $\mathrm{y}$ & Household income \\
\hline ed1 & Household head is illiterate \\
\hline ed2 & Education level of household head is primary school \\
\hline ed3 & Education level of household head is high school \\
\hline ed4 & Education level of household head is college and above \\
\hline age & Age of household head \\
\hline marriage & The marital status of the household head (married $=1$ ) \\
\hline size & Number of household members \\
\hline urban & Register of the household (urban $=1$ if in urban areas) \\
\hline east & Location of household (middle $=1$ if in Eastern China) \\
\hline middle & Location of household (middle $=1$ if in Central China) \\
\hline west & Location of household (west = 1 if in Western China) \\
\hline
\end{tabular}

Second, to calculate carbon emission intensity for each sector, we apply China's input-output table for 35 sectors for 2007 and sectoral $\mathrm{CO}_{2}$ emissions data from WIOD. After merging the 35 sectors into 32 sectors, we then disaggregate the 24 specific expenditure items into 32 sectors based on information from China's input-output table for 135 sectors for 2007. All the prices of goods and services in 2013 are converted in constant prices of 2007. Table 2 presents key summary statistics of household carbon emissions and other variables. In addition, Figure 1 illustrates the density function of $\log$ per capita indirect carbon emissions for the whole sample, as well as for the urban and rural households, respectively.

Table 2. Summary statistics of the variables for the households.

\begin{tabular}{|c|c|c|c|c|c|c|}
\hline \multirow{2}{*}{ Variables } & \multicolumn{2}{|c|}{ All } & \multicolumn{2}{|c|}{ Urban } & \multicolumn{2}{|c|}{ Rural } \\
\hline & Mean & Std. Dev. & Mean & Std. Dev. & Mean & Std. Dev. \\
\hline $\mathrm{CO}_{2}$ (tons) & 6.299 & 6.251 & 8.018 & 6.849 & 4.719 & 5.165 \\
\hline $\mathrm{y}\left(\right.$ Yuan $\left.^{*} 10^{4}\right)$ & 3.030 & 3.241 & 3.968 & 3.576 & 2.168 & 2.618 \\
\hline ed1 & 0.328 & 0.470 & 0.234 & 0.423 & 0.415 & 0.493 \\
\hline ed2 & 0.242 & 0.428 & 0.215 & 0.411 & 0.267 & 0.443 \\
\hline ed3 & 0.389 & 0.488 & 0.474 & 0.499 & 0.312 & 0.463 \\
\hline ed4 & 0.040 & 0.196 & 0.077 & 0.267 & 0.0056 & 0.074 \\
\hline age & 62.24 & 9.832 & 62.25 & 9.986 & 62.24 & 9.689 \\
\hline marriage & 0.786 & 0.410 & 0.776 & 0.417 & 0.795 & 0.404 \\
\hline size & 3.486 & 1.796 & 3.294 & 1.624 & 3.662 & 1.924 \\
\hline urban & 0.479 & 0.500 & - & - & - & - \\
\hline middle & 0.394 & 0.489 & 0.418 & 0.493 & 0.372 & 0.483 \\
\hline west & 0.237 & 0.425 & 0.177 & 0.382 & 0.292 & 0.455 \\
\hline Obs. & \multicolumn{2}{|c|}{28,284} & \multicolumn{2}{|c|}{13,541} & \multicolumn{2}{|c|}{14,743} \\
\hline
\end{tabular}

While the data we used in this paper are different from other studies, we can still see that our calculations of indirect carbon emissions are very reliable. For example, the average per capita indirect carbon emission for all Chinese older households is 6.299/3.486 = 1.81 tons in 2013, which is in line with the average per capita $\mathrm{CO}_{2}$ emissions (1.7 tons) in China in 2012 [23]. Moreover, the urbanization rate is $47.9 \%$ in 2013 , which is smaller than that of $53.73 \%$ calculated by the National Bureau of Statistics of China. In addition, the average per capita indirect $\mathrm{CO}_{2}$ emissions are 3.03 tons for urban households and 1.29 tons for rural households, respectively, which indicates that there is a large gap of indirect carbon emissions between urban and rural households. Furthermore, when looking at the density of $\log$ per capita indirect $\mathrm{CO}_{2}$ emissions in Figure 1, we notice that there is also a large disparity in indirect $\mathrm{CO}_{2}$ emissions among urban or rural households, which has been found in several studies $[18,19,23]$. 


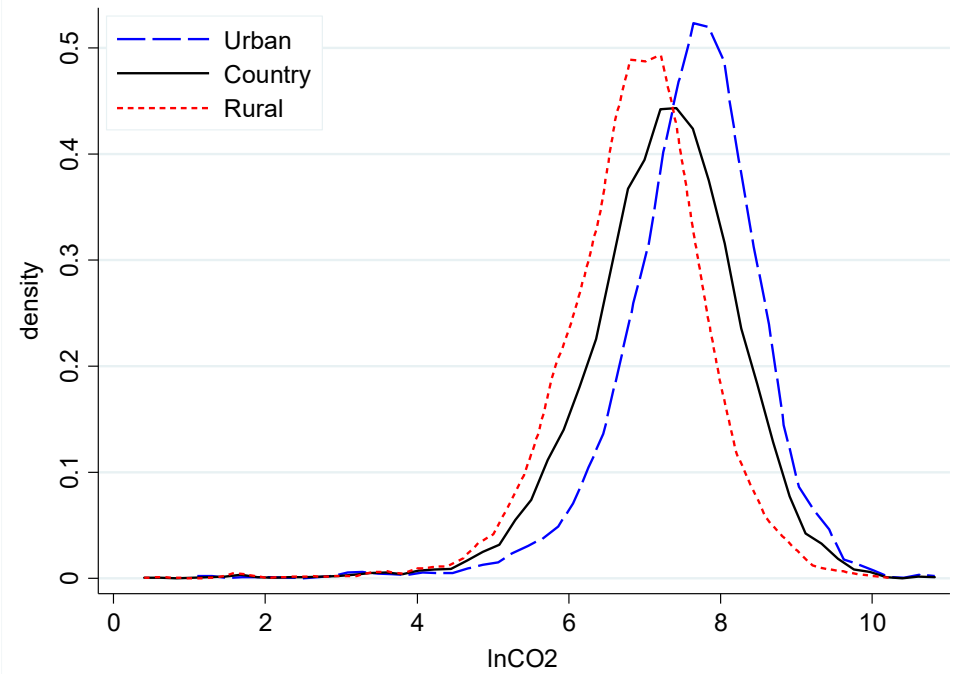

Figure 1. Density of log per capita indirect $\mathrm{CO}_{2}$ emissions.

\section{Results}

\subsection{Effects of Urbanization on Indirect Carbon Emissions}

To explore the association between urbanization and indirect $\mathrm{CO}_{2}$ emissions over the quantiles of the dependent variable, we first perform UQR with data from the whole sample. Table 3 reports the estimated coefficients of log per capita indirect $\mathrm{CO}_{2}$ emissions on the probable influencing factors for the 10th, 25th, 50th, 75th, and the 90th quantiles. The results from UQR and standard OLS are shown in Table 3. Furthermore, Figure 2 gives the plot of coefficients of urbanization on household $\mathrm{CO}_{2}$ emissions at different quantiles.

Table 3. Determinants of per capita indirect $\mathrm{CO}_{2}$ emissions in China.

\begin{tabular}{|c|c|c|c|c|c|c|}
\hline Variables & uq10 & uq25 & uq50 & uq75 & uq90 & OLS \\
\hline $\ln y$ & $\begin{array}{c}0.154^{* * *} \\
(0.012)\end{array}$ & $\begin{array}{c}0.127^{* * *} \\
(0.007)\end{array}$ & $\begin{array}{c}0.143^{* * *} \\
(0.005)\end{array}$ & $\begin{array}{c}0.175^{* * *} \\
(0.005)\end{array}$ & $\begin{array}{c}0.184^{* * *} \\
(0.007)\end{array}$ & $\begin{array}{c}0.152 \text { *** } \\
(0.005)\end{array}$ \\
\hline ed2 & $\begin{array}{c}0.130^{* * *} \\
(0.037)\end{array}$ & $\begin{array}{c}0.109 * * * \\
(0.022)\end{array}$ & $\begin{array}{c}0.066^{* * *} \\
(0.016)\end{array}$ & $\begin{array}{l}0.028 * \\
(0.016)\end{array}$ & $\begin{array}{c}0.040 * * \\
(0.019)\end{array}$ & $\begin{array}{c}0.073^{* * *} \\
(0.014)\end{array}$ \\
\hline ed3 & $\begin{array}{c}0.326^{* * *} \\
(0.032)\end{array}$ & $\begin{array}{c}0.281^{* * *} \\
(0.020)\end{array}$ & $\begin{array}{c}0.279^{* * *} \\
(0.016)\end{array}$ & $\begin{array}{c}0.217^{* * *} \\
(0.016)\end{array}$ & $\begin{array}{c}0.206^{* * *} \\
(0.021)\end{array}$ & $\begin{array}{c}0.256^{* * *} \\
(0.014)\end{array}$ \\
\hline ed4 & $\begin{array}{c}0.235^{* * *} \\
(0.040)\end{array}$ & $\begin{array}{c}0.337^{* * * *} \\
(0.025)\end{array}$ & $\begin{array}{c}0.471^{* * *} \\
(0.026)\end{array}$ & $\begin{array}{c}0.756^{* * *} \\
(0.039)\end{array}$ & $\begin{array}{c}1.048^{* * *} \\
(0.072)\end{array}$ & $\begin{array}{c}0.510 * * * \\
(0.029)\end{array}$ \\
\hline age & $\begin{array}{c}-0.017^{* * * *} \\
(0.001)\end{array}$ & $\begin{array}{c}-0.013^{* * *} \\
(0.001)\end{array}$ & $\begin{array}{c}-0.008^{* * *} \\
(0.001)\end{array}$ & $\begin{array}{c}-0.003^{* * *} \\
(0.001)\end{array}$ & $\begin{array}{c}-0.005^{* * *} \\
(0.001)\end{array}$ & $\begin{array}{c}-0.011^{* * *} \\
(0.001)\end{array}$ \\
\hline marriage & $\begin{array}{c}0.345^{* * *} \\
(0.035)\end{array}$ & $\begin{array}{c}0.127^{* * * *} \\
(0.020)\end{array}$ & $\begin{array}{c}0.031^{* *} \\
(0.015)\end{array}$ & $\begin{array}{l}-0.015 \\
(0.016)\end{array}$ & $\begin{array}{c}-0.149^{* * *} \\
(0.023)\end{array}$ & $\begin{array}{c}0.068^{* * *} \\
(0.013)\end{array}$ \\
\hline size & $\begin{array}{c}-0.146^{* * *} \\
(0.008)\end{array}$ & $\begin{array}{c}-0.129 * * * \\
(0.005)\end{array}$ & $\begin{array}{c}-0.137^{* * *} \\
(0.003)\end{array}$ & $\begin{array}{c}-0.120^{* * *} \\
(0.003)\end{array}$ & $\begin{array}{c}-0.111^{* * *} \\
(0.004)\end{array}$ & $\begin{array}{c}-0.130 * * * \\
(0.003)\end{array}$ \\
\hline urban & $\begin{array}{c}0.450^{* * *} \\
(0.025)\end{array}$ & $\begin{array}{c}0.484^{* * *} \\
(0.016)\end{array}$ & $\begin{array}{c}0.527^{* * * *} \\
(0.013)\end{array}$ & $\begin{array}{c}0.466^{* * *} \\
(0.014)\end{array}$ & $\begin{array}{c}0.300^{* * *} \\
(0.017)\end{array}$ & $\begin{array}{c}0.447^{* * *} \\
(0.011)\end{array}$ \\
\hline midd & $\begin{array}{c}0.068^{* * *} \\
(0.026)\end{array}$ & $\begin{array}{l}-0.014 \\
(0.016)\end{array}$ & $\begin{array}{c}-0.025 * \\
(0.013)\end{array}$ & $\begin{array}{c}-0.033^{* *} \\
(0.015)\end{array}$ & $\begin{array}{c}-0.046^{* *} \\
(0.020)\end{array}$ & $\begin{array}{l}-0.018 \\
(0.012)\end{array}$ \\
\hline west & $\begin{array}{c}0.092^{* * *} \\
(0.034)\end{array}$ & $\begin{array}{c}-0.086^{* * *} \\
(0.020)\end{array}$ & $\begin{array}{c}-0.108^{* * *} \\
(0.016)\end{array}$ & $\begin{array}{c}-0.085^{* * * *} \\
(0.016)\end{array}$ & $\begin{array}{c}-0.067^{* * *} \\
(0.021)\end{array}$ & $\begin{array}{c}-0.068^{* * *} \\
(0.014)\end{array}$ \\
\hline _cons & $\begin{array}{c}6.252^{* * *} \\
(0.111)\end{array}$ & $\begin{array}{c}6.973^{* * *} \\
(0.068)\end{array}$ & $\begin{array}{c}7.336^{* * *} \\
(0.054)\end{array}$ & $\begin{array}{c}7.467 * * * \\
(0.060)\end{array}$ & $\begin{array}{c}8.235^{* * *} \\
(0.081)\end{array}$ & $\begin{array}{c}7.371^{* * *} \\
(0.049)\end{array}$ \\
\hline Obs. & 28284 & 28,284 & 28,284 & 28,284 & 28,284 & 28,284 \\
\hline
\end{tabular}

Note: ${ }^{* * *} p<0.01,{ }^{* *} p<0.05,{ }^{*} p<0.1$. 


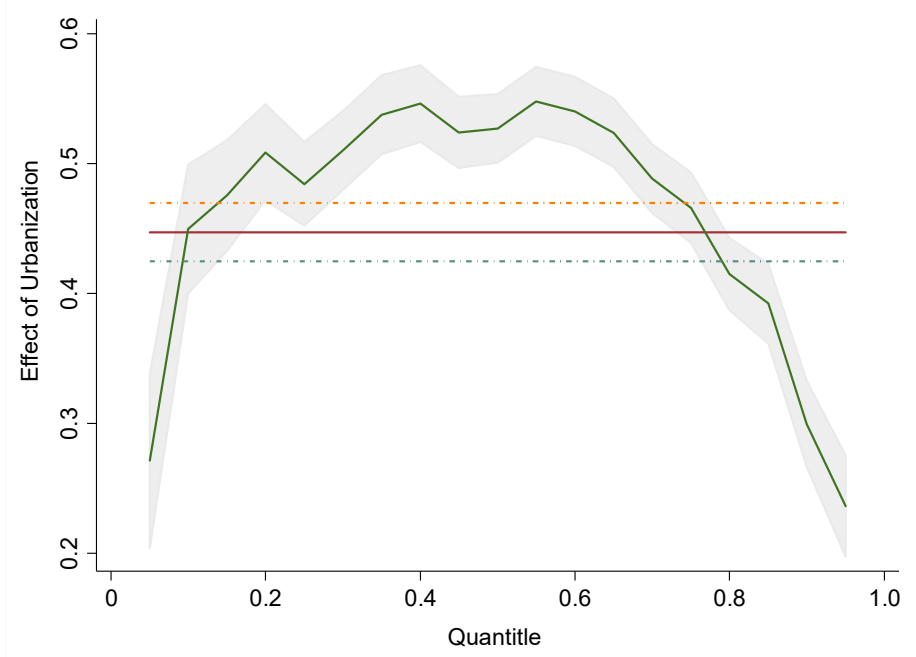

Figure 2. Effects of urbanization on per capita indirect carbon emissions. Note: Horizontal line represents the standard OLS estimates with a confidence interval (dashed lines). Households to the left (right) of the horizontal axis are those with low (high) carbon emissions. The shaded areas are confidence intervals of UQR estimates.

Overall, as shown in Table 3, income, marital status, and the education of all levels are positively correlated with indirection carbon emissions. Furthermore, the higher the education level is, the larger the effect on indirect carbon emissions is. Similar to the results from other studies where larger households are associated with lower levels of per capita energy use in the Organization for Economic Co-operation and Development (OECD) countries [47], we also notice that there is a negative relationship between indirect carbon emissions and household size, which indicates the existence of economies of scales for households.

As shown in Table 3 and Figure 2, the coefficients of urbanization at most quantiles are positive. Note that Firpo et al. provided the interpretation of the coefficient on the dummy variable by UQR [44], we may conclude that, if the coefficient on urbanization takes a value of 1 , then it can be interpreted as the impact on indirect carbon emissions for raising the proportion of population living in urban areas by one percentage. On average, one percentage point increase in the share of urban households in total households raises indirect carbon emissions by $0.447 \%$. However, the effects of urbanization on indirect carbon emissions are not evenly distributed. As can be seen from Figure 2, the impacts of urbanization on per capita indirect carbon emissions becomes much stronger since it moves from the low carbon emitters to the middle carbon emitters. Then it moves down to the high-carbon emitters, which means that there exists an inverted U-shaped curve. As a result, the inverted U-shaped curve indicates that one percentage point increase in the share of the urban households in total households gives rise to indirect carbon emissions more at the middle than at the top or the bottom. In other words, the rise of the urbanization level helps reduce the indirect carbon emission inequality.

Not surprisingly, urbanization has a positive impact on household $\mathrm{CO}_{2}$ emissions. With the rapid progress of urbanization in China, residents keep moving from rural to urban areas, and are faced with all kinds of transformations, including housing, energy consumption, commuting modes, and lifestyles, even though the incomes remain unchanged. All these will result in rapid increases in household $\mathrm{CO}_{2}$ emissions. Moreover, there exists an inverted U-shaped curve regarding the effects of urbanization on household carbon emissions, which indicates that urbanization tends to increase carbon emissions more at the middle than at the top or the bottom. Therefore, the rise of the urbanization level may lead to more carbon emissions in its early stage and reduce the inequality in household carbon emission. 


\subsection{Determinants of Per Capita Indirect Carbon Emissions in Urban China}

As previously mentioned, because clear urban-rural discrepancies of energy utilization and the related carbon emissions can be observed in China, it is imperative to examine the determinants of indirect $\mathrm{CO}_{2}$ emissions in urban and rural China, respectively. Table 4 presents the results from UQR using a sample of 13,541 observations in urban households in China. To be concise, Table 4 only provides the UQR results at the 25th percentile, 50th percentile, and 75th percentile. For the sake of comparability, Table 4 also presents the standard OLS estimates with standard errors.

Table 4. Determinants of per capita indirect $\mathrm{CO}_{2}$ emissions in urban China.

\begin{tabular}{ccccc}
\hline Variables & $\mathbf{u q 2 5}$ & $\mathbf{u q 5 0}$ & $\mathbf{u q 7 5}$ & OLS \\
\hline lny & $0.232^{* * * *}$ & $0.197^{* * *}$ & $0.172^{* * *}$ & $0.206^{* * *}$ \\
& $(0.011)$ & $(0.007)$ & $(0.008)$ & $(0.007)$ \\
ed2 & $0.174^{* * *}$ & $0.142^{* * *}$ & -0.033 & $0.115^{* * *}$ \\
& $(0.034)$ & $(0.022)$ & $(0.022)$ & $(0.021)$ \\
ed3 & $0.499^{* * *}$ & $0.299^{* * *}$ & $0.151^{* * *}$ & $0.341^{* * *}$ \\
& $(0.030)$ & $(0.021)$ & $(0.022)$ & $(0.020)$ \\
ed4 & $0.575^{* * *}$ & $0.490^{* * *}$ & $0.521^{* * *}$ & $0.528^{* * *}$ \\
& $(0.037)$ & $(0.030)$ & $(0.039)$ & $\left(0.031^{* * *}\right)$ \\
age & $-0.004^{* * *}$ & $-0.004^{* * *}$ & $-0.003^{* * *}$ & $-0.007^{* * *}$ \\
& $(0.001)$ & $(0.001)$ & $(0.001)$ & $(0.001)$ \\
marriage & $0.204^{* * *}$ & $0.075^{* * *}$ & $-0.069^{* * *}$ & $0.103^{* * *}$ \\
& $(0.026)$ & $(0.018)$ & $(0.021)$ & $(0.018)$ \\
size & $-0.182^{* * *}$ & $-0.154^{* * *}$ & $-0.126^{* * *}$ & $-0.163^{* * *}$ \\
& $(0.007)$ & $(0.005)$ & $(0.005)$ & $(0.005)$ \\
midd & $-0.081^{* * *}$ & $-0.068^{* * *}$ & $-0.082^{* * *}$ & $-0.081^{* * *}$ \\
& $(0.021)$ & $(0.016)$ & $(0.018)$ & $(0.016)$ \\
west & $-0.294^{* * *}$ & $-0.187^{* * *}$ & $-0.192^{* * *}$ & $-0.194^{* * *}$ \\
& $(0.030)$ & $(0.021)$ & $(0.021)$ & $(0.020)$ \\
cons & $6.580^{* * *}$ & $7.345^{* * *}$ & $8.015^{* * *}$ & $7.385^{* * *}$ \\
& $(0.093)$ & $(0.068)$ & $(0.075)$ & $(0.067)$ \\
$\mathrm{N}$ & $13,541^{* *}$ & 13,541 & 13,541 & $13,541^{*}$ \\
\hline
\end{tabular}

Similar to the estimates in Table 3 from the whole sample, the impact of income on indirect carbon emissions for urban China is positive. Meanwhile, income tends to increase indirect carbon emissions both for high carbon emitters and low carbon emitters. On average, a 10-percentage point increase in income raises the indirect carbon emissions by $2.06 \%$. However, the effect of income on log per capita indirect $\mathrm{CO}_{2}$ at the bottom is larger than at the top, and it decreases from 0.232 at the 25th quantile to 0.197 at the 50th quantile and reaches 0.172 at the 75 th quantile. This means that the increase of income helps decrease the carbon emissions' inequality of the urban households.

Furthermore, in most cases, there is a positive relationship between indirect carbon emissions and education of the household head. Similarly, the higher the education level is, the more the household indirect carbon emissions are. Since education leads to more carbon emissions at the bottom than at the top, it also helps reduce carbon emission inequality. We can also see that the number of household members is negatively associated with indirect $\mathrm{CO}_{2}$ emissions. Compared to the estimates 0.103 from the OLS results, the coefficient on the marital status decreases from 0.204 at the 25 th quantile to 0.075 at the 50th quantile, before turning negative $(-0.069)$ at the 75 th quantile. Not surprisingly, the location of economic regions helps reduce household indirect carbon emissions. What draws more attention is that the age of the household head is negatively associated with indirect $\mathrm{CO}_{2}$ emissions and there is no significant difference among the three quantiles. 


\subsection{Determinants of Per Capita Indirect $\mathrm{CO}_{2}$ Emissions in Rural China}

Table 5 presents the estimation results for $\log$ per capita indirect $\mathrm{CO}_{2}$ in rural China. As can be seen from Table 5, income tends to increase carbon emissions for all quantiles. On average, a 10-percentage point increase in income gives rise to indirect carbon emissions by $0.96 \%$. Meanwhile, there is also a positive relationship between $\mathrm{CO}_{2}$ emissions and education of all levels. We still see that the higher the education level is, the more the carbon emissions are. As expected, household size also helps decrease carbon emissions. However, the coefficient on the location of the economic region is not significant at most of the quantiles in this situation. Similar to the results for urban households, age also helps reduce carbon emissions at all quantiles.

Table 5. Determinants of per capita indirect $\mathrm{CO}_{2}$ emissions in rural China.

\begin{tabular}{ccccc}
\hline Variables & $\mathbf{u q 2 5}$ & $\mathbf{u q 5 0}$ & $\mathbf{u q 7 5}$ & OLS \\
\hline lny & $0.094^{* * * *}$ & $0.086^{* * *}$ & $0.102^{* * *}$ & $0.096^{* * *}$ \\
& $(0.009)$ & $(0.007)$ & $(0.007)$ & $(0.006)$ \\
ed2 & $0.094^{* * *}$ & $0.055^{* * *}$ & -0.003 & $0.044^{* *}$ \\
ed3 & $(0.029)$ & $(0.021)$ & $(0.021)$ & $(0.019)$ \\
& $0.285^{* * *}$ & $0.117^{* * *}$ & $0.090^{* * *}$ & $0.141^{* * *}$ \\
ed4 & $(0.028)$ & $(0.022)$ & $(0.023)$ & $(0.019)$ \\
& $0.532^{* * *}$ & $0.157^{* *}$ & $0.266^{* * *}$ & $0.361^{* * *}$ \\
age & $(0.071)$ & $(0.104)$ & $(0.130)$ & $(0.099)$ \\
& $-0.016^{* * *}$ & $-0.016^{* * *}$ & $-0.013^{* * *}$ & $-0.018^{* * *}$ \\
marriage & $(0.001)$ & $(0.001)$ & $(0.001)$ & $(0.001)$ \\
& $0.112^{* * *}$ & -0.022 & -0.036 & $0.046^{* *}$ \\
size & $(0.030)$ & $(0.022)$ & $(0.022)$ & $(0.020)$ \\
& $-0.120^{* * *}$ & $-0.108^{* * *}$ & $-0.107^{* * *}$ & $-0.1077^{* * *}$ \\
middle & $(0.006)$ & $(0.004)$ & $(0.004)$ & $(0.004)$ \\
& 0.034 & $0.033^{*}$ & -0.004 & $0.042^{* *}$ \\
west & $(0.025)$ & $(0.020)$ & $(0.020)$ & $(0.018)$ \\
& 0.031 & $-0.039^{*}$ & -0.007 & 0.015 \\
_cons & $(0.028)$ & $(0.021)$ & $(0.022)$ & $(0.019)$ \\
& $7.221^{* * *}$ & $7.991^{* * *}$ & $8.273^{* * *}$ & $7.916^{* * *}$ \\
N & $(0.108)$ & $(0.081)$ & $(0.083)$ & $(0.073)$ \\
& 14,743 & 14,743 & 14,743 & 14,743 \\
\hline
\end{tabular}

Note: ${ }^{* * *} p<0.01,{ }^{* *} p<0.05,{ }^{*} p<0.1$.

\subsection{Different Effects of Determinants between Urban and Rural Households}

The results in Tables 4 and 5 strongly confirm the point discussed above that there exist significant differences in the determinants of indirect $\mathrm{CO}_{2}$ emissions between urban and rural households. The differences between the estimated impacts of income and education levels on $\mathrm{CO}_{2}$ emissions for urban and rural households are illustrated in more detail in Figures 3-6, which plot the UQR estimates of income and education of different levels with their confidence interval (shaded areas) at different quantiles. The results are compared with standard OLS estimates (horizontal lines) and its confidence intervals (dashed lines) at the corresponding quantiles. 


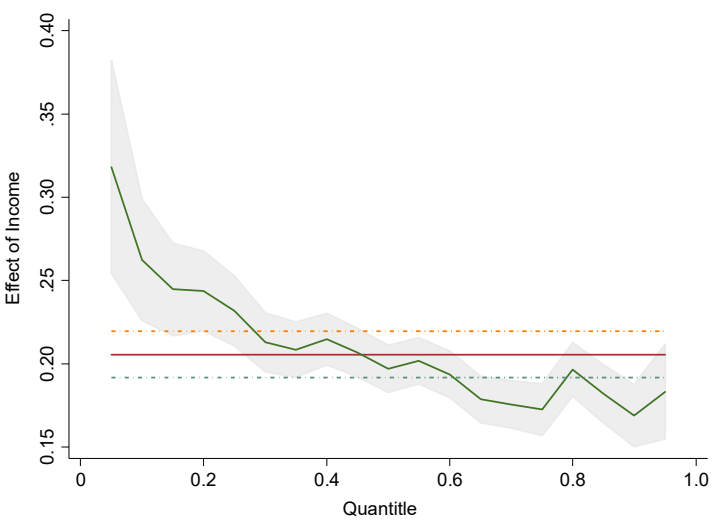

(a)

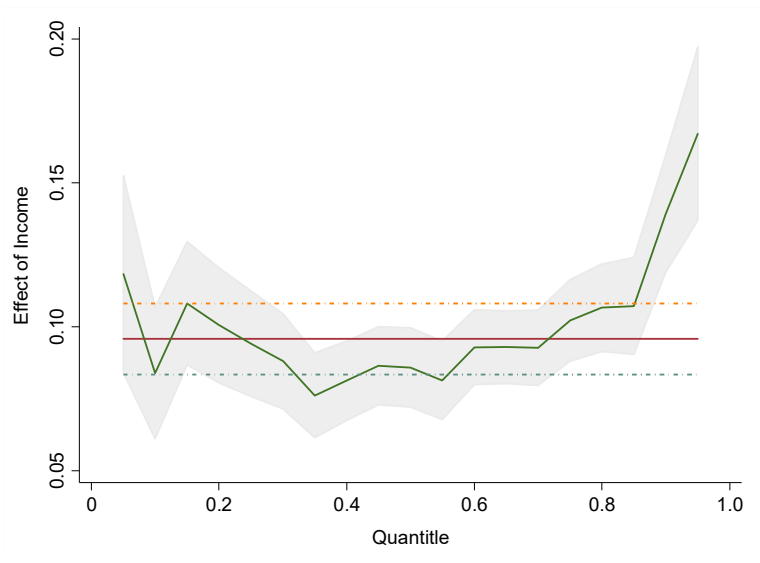

(b)

Figure 3. (a) Effects of income on $\log$ per capita indirect $\mathrm{CO}_{2}$ emissions of urban households. (b) Effects of income on $\log$ per capita indirect $\mathrm{CO}_{2}$ emissions of rural households.

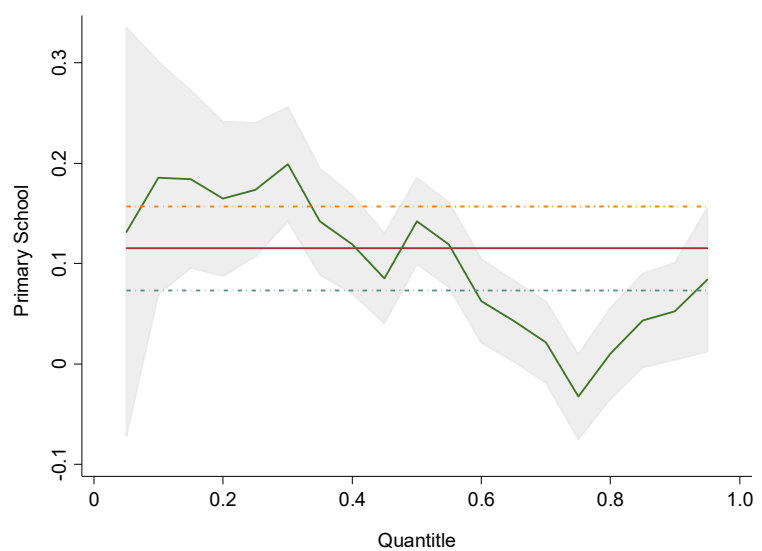

(a)

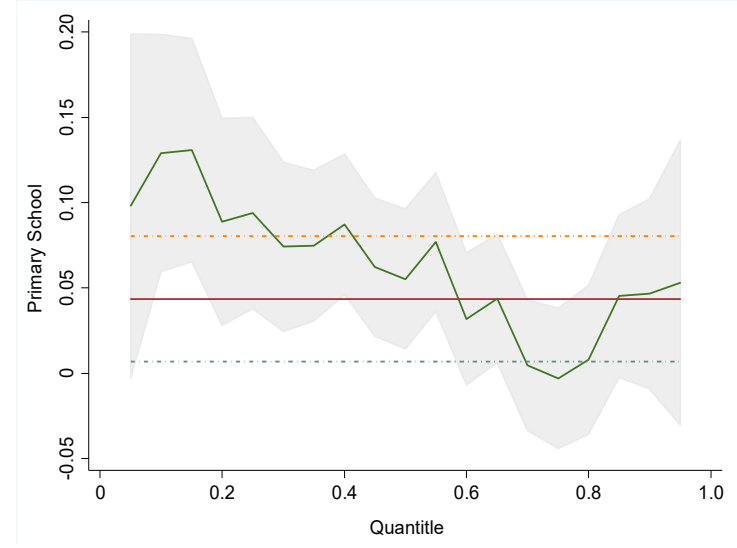

(b)

Figure 4. (a) The plot of the OLS and unconditional quantile regressions for primary school for urban households. (b) The plot of the OLS and unconditional quantile regressions for primary school for rural households.

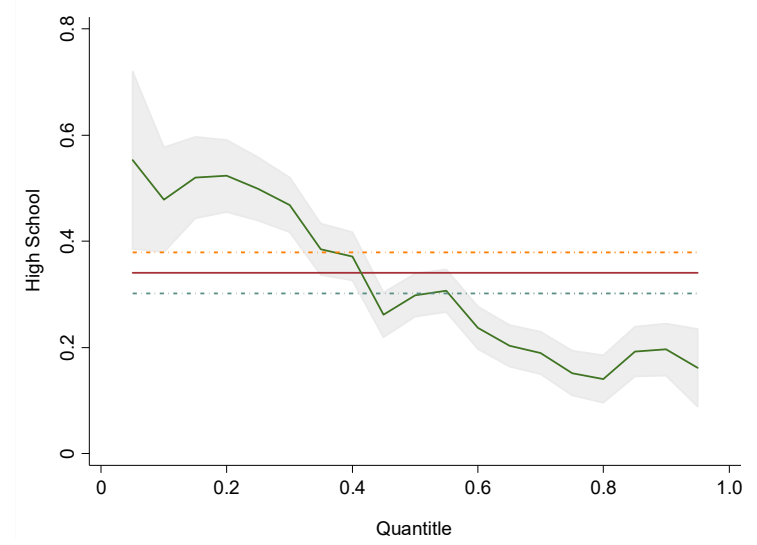

(a)

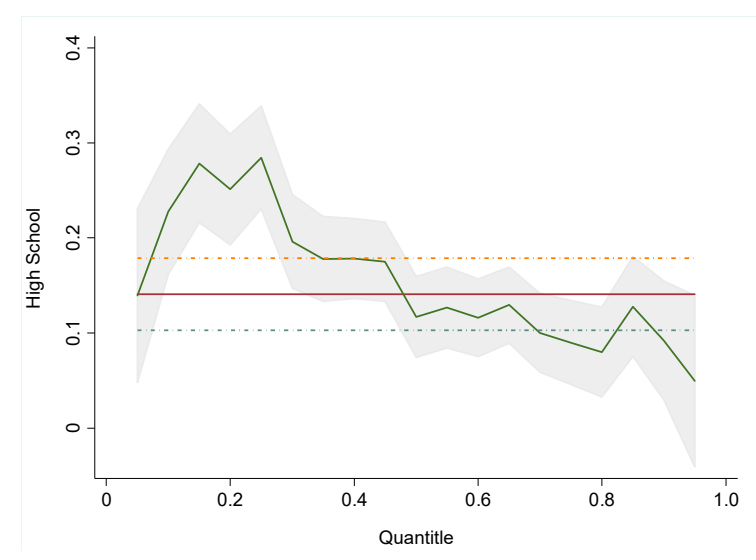

(b)

Figure 5. (a) The plot of the OLS and unconditional quantile regressions for high school for urban households. (b) The plot of the OLS and unconditional quantile regressions for high school for rural households. 


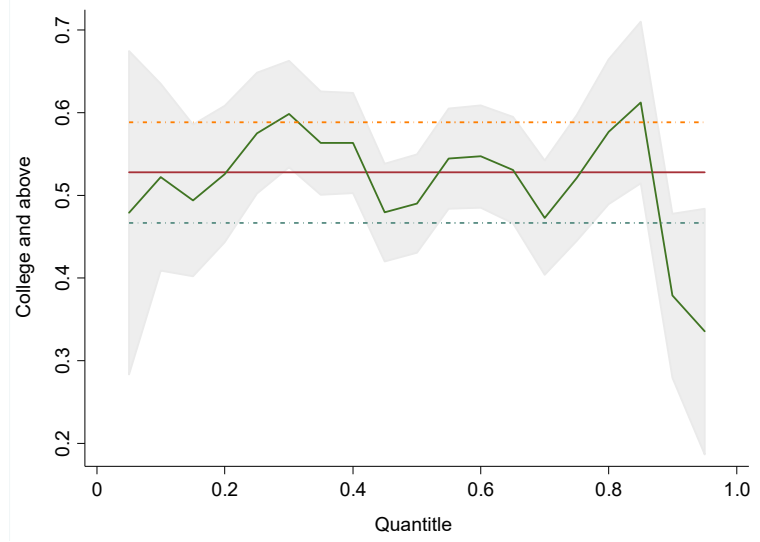

(a)

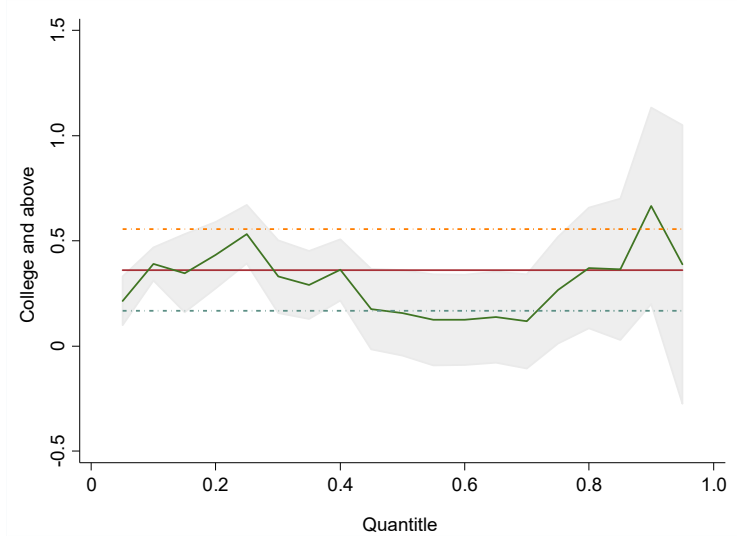

(b)

Figure 6. (a) The plot of the OLS and unconditional quantile regressions for college and above for urban households. (b) The plot of the OLS and unconditional quantile regressions for college and above for rural households.

\subsubsection{Income}

As indicated in Figure 3, the effect of income on indirect $\mathrm{CO}_{2}$ emissions for urban households is very different from that of rural households. Though the coefficients on income are both positive for urban and rural households, the OLS estimate of income for urban households is 0.206 , which is twice of the value for rural households (0.096). In addition, the effect of income on indirect $\mathrm{CO}_{2}$ emissions for urban households is smaller at the high quantiles than that at the lower quantiles. However, the effect of income on indirect $\mathrm{CO}_{2}$ emissions of rural households decreases until it reaches the 35th quantile, and then increases slowly and rapidly rises after it passes the 80th quantile.

As expected, rich households usually generate more carbon emissions per capita, which has been repeatedly confirmed in the literature [34]. However, this paper applies UQR to urban and rural households, respectively, and finds that the impacts of income on household carbon emissions are much more complex. On one hand, we find that the average effect of income on household $\mathrm{CO}_{2}$ emissions of urban households is much larger than that of rural households. While income and consumption of rural households have grown faster than that of urban households recently, there are still serious inequalities in income and carbon emissions between urban and rural households. Higher income elasticity of $\mathrm{CO}_{2}$ emissions of urban households implies that inequality in carbon emissions will continue to expand. On the other hand, there are clear urban-rural discrepancies in the effects of income on household carbon emission over different quantiles. To be more specific, for urban households, the impact of income on household $\mathrm{CO}_{2}$ emissions decreases monotonously with the increase of carbon emissions, but, for rural households, it starts to increase when it passes the 35th quantile. All these together indicate that, if the trends continue, inequality in household carbon emissions will decrease in urban areas as well as rise in rural areas.

\subsubsection{Education}

Looking at the relationship between indirect $\mathrm{CO}_{2}$ emissions and education of the household head illustrates the differences between urban and rural households. Considering, for example, the household head with primary school education, we can see that the coefficient is larger at the low quantile than that of the high quantile for both the urban and rural households. On average, a 10-percentage point increase in the share of the household head have primary school education leads to an increase of indirect carbon emissions by $1.15 \%$ for urban households, which is more than $0.44 \%$ for rural households. In addition, we can see from Figure 4 that there is more similarity in the shape of the lines between Panel (a) and (b). Similar patterns can also be seen from Panel (a) and (b) in Figure 5. For example, we can see that the coefficient on high school education from the standard OLS regression 
for urban households is 0.341 , which is much larger than that of the rural households' 0.141 . Contrary to the downward sloping line in Figures 4 and 5 both for urban and rural households, the estimated results for households with college and above education are very different between urban and rural areas. While the coefficient for urban households is much larger than that of rural households on average, there is little difference at different quantiles, both for urban and rural households.

Although research results regarding the relationship between education and household carbon emissions in the literature remain inconclusive, our results are consistent with findings from the majority of the studiers in China's case. Findings from Chinese case studies generally show a positive relationship between education and carbon emissions. Golley and Meng, for example, discovered that education is positively associated with household indirect carbon emissions because the more educated households are unaware that their relatively "sophisticated" consumption bundles are relatively carbon intensive [19]. Liu et al. also found that higher educated households in China have higher emission levels possibly because households that are better educated pursue higher living quality. They also indicated that better-educated households prefer more modern and convenient energy sources to traditional biomass, which results in more carbon emissions [48]. Li and Zhou found that a higher education ratio has a positive impact on $\mathrm{CO}_{2}$ emissions in East China [49]. Moreover, education is usually highly correlated with socio-economic status and jobs, which may promote more consumption of carbon intensive items like electronics and appliances [48,50].

With the sample of Chinese older households, we find that an increase in the share of educated households gives rise to household carbon emissions, and higher levels of education are associated with increases in carbon emissions, especially for households whose head has a degree of college and above. Two points are particularly important in this scenario. First, the education level of the household head influences consumption attitude and spending habits, which, in turn, has an effect on carbon activities even after the income factor is controlled for. Though many Chinese older households do have high levels of education, they have not received enough environmental education in the past to form awareness of environmental problems, and, thus, high education contributes little to low carbon practices. This also means that current thoughts on the role of education in affecting greener consumption choices clearly requires further validation. Second, for current Chinese older households, compared to the households with a low level of education, households with a high level of education are more likely to come from rich households, and, thus, are related with high emissions from the beginning. As a result, even if the households with a high education level have the same level of income as the households with a low education level, they may have formed the carbon-intensive consumption patterns and lifestyles and emit more carbon dioxide.

\subsubsection{Other Determinants}

As for other determinants of indirect carbon emissions, we can see from Tables 4 and 5 that the increase of the household head's age decreases indirect $\mathrm{CO}_{2}$ emissions both for urban and rural households, even though the coefficient is much larger in rural households than that of the urban households. In addition, there is a slight difference among urban or rural households at different quantiles, respectively. On average, the marital status of the household head gives rise to indirect $\mathrm{CO}_{2}$ emissions both for urban and rural households. However, the coefficient is not significant at the 50th and 75th quantile for rural households. Household size is negatively associated with indirect carbon emissions for both urban and rural households for reasons already discussed above. For the locations of economic regions, the estimated coefficients are negative at the 25th, 50th, and 75th quantiles if the household lives in Central or Western China, while the results for rural households are mixed. Furthermore, there are significant disparities in household carbon emissions among regions in China, which result from differences in income level, lifestyles, energy consumption, and climate conditions $[45,51,52]$. 


\section{Discussion}

It is widely acknowledged that deep cuts in carbon emissions are unlikely to be fulfilled through technological change alone, and it has become imperative to cut $\mathrm{CO}_{2}$ emissions from the consumption-side. Studying the determinants of household $\mathrm{CO}_{2}$ emissions can inform mitigation policy development. In view of the facts that various socio-economic groups have different $\mathrm{CO}_{2}$ emissions, as well as China experiencing rapid population aging, we focus on the key drivers of indirect $\mathrm{CO}_{2}$ emissions of older Chinese households, and analyze the heterogeneous effects of the influencing factors on household carbon emissions by applying UQR in order to put forward effective emission reduction policies.

By integrating older Chinese household survey data with the UQR model, this paper examined the heterogeneous impacts of household characteristics on indirect $\mathrm{CO}_{2}$ emissions of older Chinese households. We made efforts to strengthen the literature from the perspective of the consumption side in the context of urbanization and population aging, which provides more realistic and meaningful insights for policymakers. The input-output method in this study is more comprehensive and produces high quality estimates of indirect carbon emissions. The UQR model allows estimating the influences of the potential determinants on all parts of carbon emission distribution and is, thus, better suited to answer questions about the key drivers of carbon emissions than the standard OLS model. Identifying the key drivers of carbon emissions of older Chinese households and their heterogeneous effects on carbon emissions gives policymakers critical information on emissions reduction. First, policymakers should take measures to promote low-carbon cities development, especially in city planning, urban infrastructure, public transportation, and energy conservation. It shows policymakers that urbanization has a comprehensive impact on consumption patterns and lifestyles of older Chinese households, which may lead to more carbon emissions. Second, since households with higher education also have significantly higher incomes, we may consider that they bear higher responsibility than their counterparts for shouldering the costs of mitigating climate change, and what is really needed in education to bring significant changes in consumption behavior is a greater emphasis on the environmental philosophy [27]. Meantime, effective measures should be deployed to encourage the formation of low-carbon consumption pattern and lifestyles through education and policy instruments, such as the application of green or low-carbon labeling, introduction of fuel taxes, congestion charges, carbon taxes, and progressive electricity pricing [27]. Third, from the perspective of fairness, policymakers should design differential policies, according to households' income level, urban or rural location, and carbon emissions situations, as well as subsidize low-income residents in emission reduction activities and cut emissions effectively [53]. In addition, considering the great disparities in carbon emissions among regions in China, policymakers should design targeted policies, according to differentiated regional characteristics, in order to reduce carbon emissions in the most cost-effective way, and educational efforts should be targeted to more highly educated and affluent consumers to encourage more climate-friendly consumption choices.

However, there are some limitations worth studying in the future.

- Due to data availability, when calculating the indirect carbon emissions, we use input-output tables and sectoral $\mathrm{CO}_{2}$ emissions data from WIOD in China for 2007 to quantify emissions for 2013. Therefore, we are making an assumption that the production technology, as well as the sectoral carbon intensities in 2013, is the same as that of 2007.

- We rely on China's input-output table instead of the multi-regional input-output table to approximate emissions from imports, which means that the carbon intensities of the imported goods and services consumed by households are the same as that of goods and services produced in China. Further studies can be undertaken to measure household carbon emissions more completely by using a multi-regional input-output table.

- While input-output analysis has a certain advantage over a process-based life cycle assessment because it is more comprehensive, it is also much coarser, which makes the analysis less accurate 
and relevant [54]. As the hybrid life cycle assessment unites the precision of a process-based life cycle assessment with the comprehensiveness of input-output analysis [55], it will be very helpful to utilize the hybrid life cycle assessment in the future study.

- There are 35 sectors in China's input-output table, but we only have 24 expenditure items of goods and services in CHARLS to complete the data match and quantify the indirect carbon emissions. It would be more helpful if we have detailed consumption expenditure items.

- Considering that the research results regarding the relationship between education and household carbon emissions in the literature are inconclusive, it is of critical importance to study the influencing mechanism of education on household carbon emissions in China in future research.

- This paper only focuses on indirect carbon emissions of households whose heads are more than 45 years old, and further comparative study between households with the heads less than 45 years old and more than 45 years old will be helpful to mitigation policies.

Author Contributions: H.Z. conceived, performed the research, analyzed the data, and wrote the paper. L.Z. collected and cleaned up the data, and participated in analyzing the data. K.W. calculated household carbon emissions, participated in writing the paper, and revised the paper. X.S. contributed to introduction and policy discussions. All authors have read and approved the final manuscript.

Funding: The National Social Science Foundation of China (No. 15BTJ021, No. 14BJY047 and No. 18ZDA038), National Natural Science Foundation of China (71828401 and 71803040), and the China Postdoctoral Science Foundation (2018T110817) supported this work.

Conflicts of Interest: The authors declare no conflict of interest.

\section{References}

1. Zhang, Y.J.; Bian, X.J.; Tan, W. The linkages of sectoral carbon dioxide emission caused by household consumption in China: Evidence from the hypothetical extraction method. Empir. Econ. 2018, 54, 1743-1775. [CrossRef]

2. Bin, S.; Dowlatabadi, H. Consumer lifestyle approach to US energy use and the related $\mathrm{CO}_{2}$ emissions. Energy Policy 2005, 33, 197-208. [CrossRef]

3. Pachauri, S.; Spreng, D. Direct and indirect energy requirements of households in India. Energy Policy 2002, 30, 511-523. [CrossRef]

4. Park, H.C.; Heo, E. The direct and indirect household energy requirements in the Republic of Korea from 1980 to 2000-An input-output analysis. Energy Policy 2007, 35, 2839-2851. [CrossRef]

5. Nansai, K.; Kondo, Y.; Kagawa, S.; Suh, S.; Nakajima, K.; Inaba, R.; Tohno, S. Estimates of embodied global energy and air-emission intensities of japanese products for building a Japanese input-output life cycle assessment database with a global system boundary. Environ. Sci. Technol. 2012, 46, 9146-9154. [CrossRef] [PubMed]

6. Hamamoto, M. Energy-saving behavior and marginal abatement cost for household $\mathrm{CO}_{2}$ emissions. Energy Policy 2013, 63, 809-813. [CrossRef]

7. Markaki, M.; Belegri-Roboli, A.; Sarafidis, Y.; Mirasgedis, S. The carbon footprint of Greek households (1995-2012). Energy Policy 2017, 100, 206-215. [CrossRef]

8. Liu, H.T.; Guo, J.E.; Qian, D.; Xi, Y.M. Comprehensive evaluation of household indirect energy consumption and impacts of alternative energy policies in China by input-output analysis. Energy Policy 2009, 37, 3194-3204. [CrossRef]

9. Yang, Y.; Zhao, T.; Wang, Y.; Shi, Z. Research on impacts of population-related factors on carbon emissions in Beijing from 1984 to 2012. Environ. Impact Assess. Rev. 2015, 55, 45-53. [CrossRef]

10. Zhang, C.; Tan, Z. The relationships between population factors and China's carbon emissions: Does population aging matter? Renew. Sustain. Energy Rev. 2016, 65, 1018-1025. [CrossRef]

11. Dalton, M.; O’Neill, B.; Prskawetz, A.; Jiang, L.; Pitkin, J. Population aging and future carbon emissions in the United States. Energy Econ. 2008, 30, 642-675. [CrossRef]

12. Zhang, X.; Luo, L.; Skitmore, M. Household carbon emission research: An analytical review of measurement, influencing factors and mitigation prospects. J. Clean. Prod. 2015, 103, 873-883. [CrossRef] 
13. Yuan, B.; Ren, S.; Chen, $X$. The effects of urbanization, consumption ratio and consumption structure on residential indirect $\mathrm{CO}_{2}$ emissions in China: A regional comparative analysis. Appl. Energy 2015, 140, 94-106. [CrossRef]

14. Ma, X.W.; Du, J.; Zhang, M.Y.; Ye, Y. Indirect carbon emissions from household consumption between China and the USA: Based on an input-output model. Nat. Hazards 2016, 84, 399-410. [CrossRef]

15. Shen, W.; Cao, L.; Li, Q.; Zhang, W.; Wang, G.; Li, C. Quantifying $\mathrm{CO}_{2}$ emissions from China's cement industry. Renew. Sustain. Energy Rev. 2015, 50, 1004-1012. [CrossRef]

16. Heinonen, J.; Junnila, S. A carbon consumption comparison of rural and urban lifestyles. Sustainability 2011, 3, 1234-1249. [CrossRef]

17. Feng, Z.H.; Zou, L.L.; Wei, Y.M. The impact of household consumption on energy use and $\mathrm{CO}_{2}$ emissions in China. Energy 2011, 36, 656-670. [CrossRef]

18. Xu, X.; Han, L.; Lv, X. Household carbon inequality in urban China, its sources and determinants. Ecol. Econ. 2016, 128, 77-86. [CrossRef]

19. Golley, J.; Meng, X. Income inequality and carbon dioxide emissions: The case of Chinese urban households. Energy Econ. 2012, 34, 1864-1872. [CrossRef]

20. Zhang, L.X.; Wang, C.B.; Bahaj, A.S. Carbon emissions by rural energy in China. Renew. Energy 2014, 66, 641-649. [CrossRef]

21. Wang, Z.; Liu, W.; Yin, J. Driving forces of indirect carbon emissions from household consumption in China: An input-output decomposition analysis. Nat. Hazards 2015, 75, 257-272. [CrossRef]

22. López, L.A.; Arce, G.; Morenate, M.; Monsalve, F. Assessing the Inequality of Spanish Households through the Carbon Footprint: The 21st Century Great Recession Effect. J. Ind. Ecol. 2016, 20, 571-581. [CrossRef]

23. Wiedenhofer, D.; Guan, D.; Liu, Z.; Meng, J.; Zhang, N.; Wei, Y.M. Unequal household carbon footprints in China. Nat. Clim. Chang. 2017, 7, 75-80. [CrossRef]

24. Sommer, M.; Kratena, K. The Carbon Footprint of European Households and Income Distribution. Ecol. Econ. 2017, 136, 62-72. [CrossRef]

25. Brand, C.; Goodman, A.; Rutter, H.; Song, Y.; Ogilvie, D. Associations of individual, household and environmental characteristics with carbon dioxide emissions from motorised passenger travel. Appl. Energy 2013, 104, 158-169. [CrossRef]

26. Sun, C.; Ouyang, X.; Cai, H.; Luo, Z.; Li, A. Household pathway selection of energy consumption during urbanization process in China. Energy Convers. Manag. 2014, 84, 295-304. [CrossRef]

27. Han, L.; Xu, X.; Han, L. Applying quantile regression and Shapley decomposition to analyzing the determinants of household embedded carbon emissions: Evidence from urban China. J. Clean. Prod. 2015, 103, 219-230. [CrossRef]

28. Allinson, D.; Irvine, K.N.; Edmondson, J.L.; Tiwary, A.; Hill, G.; Morris, J.; Bell, M.; Davies, Z.G.; Firth, S.K.; Fisher, J.; et al. Measurement and analysis of household carbon: The case of a UK city. Appl. Energy 2016, 164, 871-881. [CrossRef]

29. Olaniyan, O.; Dele Sulaimon, M.; Adekunle, W. Determinants of Household Direct $\mathrm{CO}_{2}$ Emissions: Empirical Evidence from Nigeria. Munich Personal RePEc Archive. 2018. Available online: https://mpra.ub.unimuenchen.de/87801/1/MPRA_paper_87801.pdf (accessed on 17 October 2019).

30. Christis, M.; Breemersch, K.; Vercalsteren, A.; Dils, E. A detailed household carbon footprint analysis using expenditure accounts-Case of Flanders (Belgium). J. Clean. Prod. 2019, 228, 1167-1175. [CrossRef]

31. Baiocchi, G.; Minx, J.; Hubacek, K. The Impact of social factors and consumer behavior on carbon dioxide emissions in the United Kingdom. J. Ind. Ecol. 2010, 14, 50-72. [CrossRef]

32. Brand, C.; Preston, J.M. "60-20 emission"-The unequal distribution of greenhouse gas emissions from personal, non-business travel in the UK. Transp. Policy 2010, 17, 9-19. [CrossRef]

33. Lenzen, M.; Wier, M.; Cohen, C.; Hayami, H.; Pachauri, S.; Schaeffer, R. A comparative multivariate analysis of household energy. Energy 2006, 31, 181-207. [CrossRef]

34. Büchs, M.; Schnepf, S.V. Who emits most? Associations between socio-economic factors and UK households' home energy, transport, indirect and total $\mathrm{CO}_{2}$ emissions. Ecol. Econ. 2013, 90, 114-123. [CrossRef]

35. Boehm, R.; Wilde, P.E.; Ver Ploeg, M.; Costello, C.; Cash, S.B. A Comprehensive Life Cycle Assessment of Greenhouse Gas Emissions from U.S. Household Food Choices. Food Policy 2018, 79, 67-76. [CrossRef]

36. Yu, B.; Wei, Y.M.; Kei, G.; Matsuoka, Y. Future scenarios for energy consumption and carbon emissions due to demographic transitions in Chinese households. Nat. Energy 2018, 3, 109-118. [CrossRef] 
37. Wilson, J.; Tyedmers, P.; Spinney, J.E.L. An exploration of the relationship between socioeconomic and well-being variables and household greenhouse gas emissions. J. Ind. Ecol. 2013, 17, 880-891. [CrossRef]

38. Zheng, H.; Hu, J.; Wang, S.; Wang, H. Examining the influencing factors of CO 2 emissions at city level via panel quantile regression: Evidence from 102 Chinese cities. Appl. Econ. 2019, 51, 3906-3919. [CrossRef]

39. Xu, X.; Han, L. Diverse effects of consumer credit on household carbon emissions at quantiles: Evidence from urban China. Sustainability 2017, 9, 1563. [CrossRef]

40. Rong, P.; Zhang, L.; Qin, Y.; Chen, S.; Sun, Y. The influencing factors of urban household embedded carbon emissions based on quantile regression. Energy Procedia 2018, 152, 738-743. [CrossRef]

41. Borah, B.J.; Basu, A. Highlighting differences between conditional and unconditional quantile regression approaches through an application to assess medication adherence. Health Econ. 2013, 22, 1052-1070. [CrossRef]

42. Timmer, M.P.; Dietzenbacher, E.; Los, B.; Stehrer, R.; de Vries, G.J. An Illustrated User Guide to the World Input-Output Database: The Case of Global Automotive Production. Rev. Int. Econ. 2015, 23, 575-605. [CrossRef]

43. Koenker, R.; Bassett, G. Regression Quantiles. Econometrica 1978, 46, 33-50. [CrossRef]

44. Firpo, B.S.; Fortin, N.M.; Lemieux, T. Unconditional Quantile Regressions. Econometrica 2009, 77, $953-973$.

45. Duarte, R.; Mainar, A.; Sánchez-Chóliz, J. The impact of household consumption patterns on emissions in Spain. Energy Econ. 2010, 32, 176-185. [CrossRef]

46. Xu, X.; Tan, Y.; Chen, S.; Yang, G.; Su, W. Urban household carbon emission and contributing factors in the Yangtze River Delta, China. PLoS ONE 2015, 10, e0121604. [CrossRef]

47. Liddle, B. Demographic dynamics and per capita environmental impact: Using panel regressions and household decompositions to examine population and transport. Popul. Environ. 2004, 26, 23-39. [CrossRef]

48. Liu, W.; Spaargaren, G.; Heerink, N.; Mol, A.P.J.; Wang, C. Energy consumption practices of rural households in north China: Basic characteristics and potential for low carbon development. Energy Policy 2013, 55, 128-138. [CrossRef]

49. Li, S.; Zhou, C. What are the impacts of demographic structure on $\mathrm{CO}_{2}$ emissions? A regional analysis in China via heterogeneous panel estimates. Sci. Total Environ. 2019, 650, 2021-2031. [CrossRef]

50. Hurth, V. Creating sustainable identities: The significance of the financially affluent self. Sustain. Dev. 2010, 18, 123-134. [CrossRef]

51. Lyons, S.; Pentecost, A.; Tol, R.S.J. Socioeconomic distribution of emissions and resource use in Ireland. J. Environ. Manag. 2012, 112, 186-198. [CrossRef]

52. Zheng, S.; Wang, R.; Glaeser, E.L.; Kahn, M.E. The greenness of China: Household carbon dioxide emissions and urban development. J. Econ. Geogr. 2011, 11, 761-792. [CrossRef]

53. Yi, H. Clean-energy policies and electricity sector carbon emissions in the U.S. states. Util. Policy 2015, 34, 19-29. [CrossRef]

54. Wiedmann, T. Editorial: Carbon footprint and input-output analysis-An introduction. J. Econ. Syst. Res. 2009, 21, 175-186. [CrossRef]

55. Teh, S.H.; Wiedmann, T.; Castel, A.; de Burgh, J. Hybrid life cycle assessment of greenhouse gas emissions from cement, concrete and geopolymer concrete in Australia. J. Clean. Prod. 2017, 152, 312-320. [CrossRef]

(C) 2019 by the authors. Licensee MDPI, Basel, Switzerland. This article is an open access article distributed under the terms and conditions of the Creative Commons Attribution (CC BY) license (http://creativecommons.org/licenses/by/4.0/). 